\title{
Multicultural Modes of Immigrants' Integration into the Host Society: Exploring the Proposition
}

\author{
Ewa Morawska \\ Department of Sociology, University of Essex, UK
}

Copyright $\mathrm{C} 2018$ by authors, all rights reserved. Authors agree that this article remains permanently open access under the terms of the Creative Commons Attribution License 4.0 International License

\begin{abstract}
In this essay, I argue that in addition to the acknowledged modes of immigrants' integration into receiver societies, such as straight-line or segmented assimilation, 'bumpy' incorporation, and ethnicization as the mixing and blending of home and host country ways of life, we should recognize the possibility of multicultural paths of newcomers' adaptation to the sociocultural environments of the host-country. I begin by defining what I mean by a multicultural trajectory of immigrants' integration as a pluri-dimensional process founded on the base-line orientation, which Lyn Lofland called 'civility towards diversity', emphasizing its inherently variegated forms and 'contents'. Next, I present some empirical illustrations of local settings where multicultural modes of immigrants' incorporation are likely to evolve. Finally, drawing from studies of inter-cultural encounters, I identify the main features of the surrounding society and the individuals involved, which contribute to the emergence of these modes of integration.
\end{abstract}

Keywords Multicultural Integration Trajectories, Local Settings, Contributing Factors

\section{Introduction}

"Across the globe, more people-from more varied cultural and linguistic backgrounds, subject to more varied conditions of mobility and legal status - come into regular contact with one another in today's growing cities" [1]. This acknowledgement by Steven Vertovec[1, p. 1] of the growing diversification of the forms and 'contents' of human interactions across the world to which increased transnational migratory flows significantly contribute has been reflected in a rapidly expanding social-science literature on 'super-diversity' and 'global neighbourhoods' [2-6], 'multiethnicity' [7], and 'multiculture' [8]. In reports on present-day (im) migrants' self-representations and pursuits one increasingly encounters individuals presenting themselves as a "Pakistani British Manchesterian in a move to Amsterdam" or a "London Pole with a Berlin flavour". In the evening edition of the Euronews on 19.01.2016, a reporter told the story of "Cypriot Turkish Armenian Danish youngsters charged with the wounding of a policeman in Stockholm".

Such multiple identities and involvements indicate developments, which elude the standard social-science conceptualization of immigrants' integration into their host societies such as straight-line or segmented assimilation, 'bumpy' and path-dependent incorporation trajectories, and ethnicization as the mixing and blending of the ways of life of the home and host countries (for good overviews of old and new assimilation theories, see Krivisto 2012 [9] and the special issue of Ethnic and Racial Studies on assimilation and integration theories 10]; Crul [11] offers an interesting discussion of how the ethnic super-diversity of present-day cities challenges accustomed assimilation theories, but proposes no alternative model[s]). In this essay, I propose that we recognize multicultural paths of immigrants' integration into the receiver society as possible trajectories of newcomers' incorporation, and I identify a constellation of conducive circumstances upon which they are contingent.

\section{Multicultural Incorporation Trajectories: Definition, Level of Operation, and Differences from Related Concepts}

I define the multicultural trajectory of immigrants' integration (I use the term interchangeably with assimilation and incorporation) into the host society as consisting of four components, which share the base-line orientation Lyn Lofland [12] called 'civility towards diversity' but vary in scope and intensity over time and depending on the context. They are: (i) symbolic identification with plural national/ethnic/religious groups resident in the host society and their traditions; (ii) 
internalization and practice of extrinsic (language, customs) and intrinsic (values, normative expectations, beliefs) components of the cultures of different national/ethnicreligious groups resident in the host society; (iii) regular social engagement with members of different national/ethnic/religious groups resident in the host society in formal, semi-formal, and/or informal settings including neighborhood public places (such as streets, shops, pubs, and eateries), workplaces, kindergartens and schools, homes and gardens; and (iv) civic commitment to/responsibility for the wellbeing of the body politic of several national/ethnic/religious communities resident in the host society. From these processes emerges the actors' experience of the host country, the locality of their residence as inherently diverse in people, languages, tastes, smells, and customs. As this definition indicates, my understanding of immigrants' multicultural integration into the host society is considerably broader, both in terms of the dimensions it covers and the players (human agents and societal structures) it involves, than the notion of "multiculturalism as civic incorporation" proposed by Peter Kivisto [13,9] and Jeffrey Alexander[14] or Will Kymlicka [15] and Charles Taylor[16]. They limit this phenomenon to one (civic) component and lay the 'burden' of immigrants' inclusion primarily on the side of the receiver societies legal system, policies, and institutions.

To be sure, immigrants may experience the identification, commitment, and practices associated with one particular group as more important than those associated with other groups, and they may turn out to be more enduring. Yet, in terms of their worth, the various commitments are perceived of in a 'horizontal' rather than 'vertical' or hierarchical fashion. Other groups/cultures are generally viewed, at a minimum, with sympathetic indifference and, at best, with what Frans de Waal [17], a world-renowned primatologist, calls empathic interest. The everyday functioning and reconstitution of such polyphonic identities and engagements by no means precludes the sort of Weltanschauung Michael Walzer[18] describes as a form of particularistic universalism, i.e., a life orientation, which combines (sub)group-specific concerns and loyalties with an identification with, and commitment to, a broader, overarching host/imagined national community, its values and purposes. Where conflicts arise between the particular and the universal components, this sort of orientation calls for a compromise-based or negotiatory (rather than zerosum/either-or) mode of resolution.

As the outlined understanding of a multicultural trajectory of immigrants' integration into the host society indicates, I suggest we think of it in terms of variant forms and 'contents' rather than as a present-or-absent condition. It is, therefore, more adequate to view it not as a singletrack development, but in the plural as multicultural trajectories. Multicultural paths of incorporation can be displayed by (and assessed in) both individual human actors and institutions on a continuum of views and practices ranging from minimum to the maximum degrees. Different components of these trajectories may also display different scopes and intensities due to changing circumstances in immigrants' lives, which alter their interests, perceptions, and everyday involvements. In other words, although some elements and emphases in possible trajectories of multicultural integration can be more firmly anchored and more enduring than others-for example, immigrants' identification with, and commitment to, the host society in which they have spent a good number of years and feel welcome - the overall composition of these evolving processes is context-dependent and situational. I would also argue that, much as they are co-shaped by the forces operating at broader societal levels, multicultural trajectories of immigrants' incorporation into the host society, because they take shape, persist, or are reconstituted through everyday intergroup relations that are felt, heard, tasted and smelled on an everyday basis, evolve at the local level, in the concrete settings where those newcomers live. On the importance of local contexts for the understanding of the operation of [super-] diverse social settings, see Clayton [19], Berg and Sigma [20] 2013, and Vertovec [1].

The concept of multicultural trajectories of immigrants' incorporation into the host society is, as I indicated, akin, but not identical, to some other earlier and current models of assimilation, such as the 'old' and 'new' pluralism, ethnic options, cosmopolitanism, and - an idea currently en vogue in social-science writings on present-day societies(super-) diversity (see the special issue of Ethnic and Racial Studies [21] on this concept). The notion of multicultural integration trajectories shares with these theories/framing concepts an appreciation of diversity as the integral feature of contemporary societies; of host institutions' obligation to recognize it as legitimate; and of immigrants' agency in expecting and acting upon this recognition. It differs, however, in important ways from each of these conceptualizations. The advocates of both the old [22-24] and the new [25] pluralism approach call for the recognition of immigrants' and their offspring's enduring ethnic identities and attachments, which come to constitute an integral part of the culture of the host-country. They therefore tend to fix in time and place or essentialize the ethnic dimension of immigrants' self-representations and practices. Against the ascriptive treatment of ethnic membership, the ethnic options model [26,27] makes immigrants and their descendants pick and choose different components from their ethnic heritage in constructing their identities. Yet like the old and new pluralism approaches it is basically premised on the idea of bi- (home- and hostcountry) rather than multi-culturalism. The revised versions of this approach recognize ethnic diversity based on people's voluntary commitments, but emphasize "the power of the integrating values of our common society" [ $[28$, p. 450]. Herbert Gans [29] has recently revised his earlier emphasis on enduring ethnic pluralism, and now assumes, 
instead, that ethnicity disappears under the impact of progressive assimilation, at least among the later descendants of European immigrants in America).

The main difference between the proposed understanding of a multicultural trajectory of immigrants' incorporation into the host society and the notion of their becoming cosmopolitan lies in the fact that the latter denotes a radical detachment from grounded communities and loyalties and perpetual fluidity of human selves and citizens (see Waldron [30] for a good review of different conceptualizations of cosmopolitanism). The "particularist-universalist" orientation, by contrast, allows for, or even invites, a more enduring commitment to particular places, groups, and/or traditions. Finally, diversity, which some scholars suggest, can be treated as "a new mode of [immigrants'] incorporation" ([31]; for a review of approaches under this label, see Wessendorf [32]) represents, I believe, a necessary prerequisite for multicultural adaptation rather than that adaptation itself.

And one last clarification before we move on to the next section. The term 'multiculturalism' has, of course, been criticized for implying ethno-religious separatism and nonrecognition of the overarching, common values, commitments, and practices of the receiver society. Hence it has been suggested that we refer to 'interculturalism' instead. Against this backdrop, my understanding of multicultural trajectories of immigrants' integration into the host society aligns me with Nasar Meer and Tariq Modood [33]. They have acknowledged an overemphasis on difference in the early conceptualizations of multiculturalism in the 1990s, but argue that its current, revised version explicitly allows for "cultural multilogues", "interactive exchanges", and "the unifying potential of the majority/national culture" (see also Taylor [34]; on interculturalism, see Bouchard [35].

The purpose of this essay is to interest migration scholars in the recognition of multicultural integration trajectories as yet another mode of immigrants' adaptation to the host society. Drawing on empirical evidence from three locations, in support of my proposition I illustrate the variety of local forms of positive engagement among different ethnic groups, and then identify the basic features of the surrounding society and its residents that seem to be necessary to facilitate the emergence of multicultural paths of assimilation to emerge.

\section{Local Settings with Everyday Intercultural Contacts: Empirical Illustrations}

From the examined studies of settings, which display everyday intercultural exchanges among the residents, I intentionally selected three cases representing varied, inner-city, middle-class urban as well as lower-middleclass suburban locations. I did so in order to demonstrate that it is not the residential layout and socioeconomic profile of the setting that determines the presence or absence of intercultural encounters (although these features are likely to shape the type and scope of such relations). None of the selected studies focus specifically on patterns of immigrants' adaptation into the host society, but they provide 'thick descriptions' of local sociocultural settings, which make multicultural trajectories of incorporation quite likely. All the selected cases come from the 'Anglo' world (United Kingdom, United States, and Australia) because it was here that I found the largest number of relevant studies. I do not believe this selection makes a difference for the general arguments advanced in this essay, but the country/state-national legal-political system, policies, and public culture of course co-shape the modes of immigrants' incorporation and, as noted in the final section of the essay on the circumstances profiling newcomers' adaptation to the host society, they should always be considered by the researchers.

In my presentation of the three cases I replicate the primary focus of the studies from which I drew these examples, namely, the local "sites of prosaic interactions" [36], rather than offering encompassing depictions of these settings including the socioeconomic and civic-political profiles and mezzo-(city-) macro-(national-)level contexts which co-shape them. I will consider these factors in the last part of the essay, which focuses on the conditions conducive to/hindering multicultural integration trajectories. In each of the three cases, I identify the features of their physical layout, urban infrastructure, and civicpolitical tradition that have shaped residents' interactions, and the main spheres and "contents" of current intergroup engagements.

We begin the review with an inner-city area-the borough of Hackney in north-east London-where the situation directly challenges the accustomed representation of such settings in social-science studies, which tends to portray them as sharply divided along ethnic/religious lines with the residents of each group leading separate lives. Everyday intergroup relations in Hackney were the subject of an ethnographic investigation by Susanne Wessendorf [37-39]. (Additional information about this neighbourhood comes from my correspondence with Wessendorf in July 2016; Neal [40]; Hackney websites).

The population of Hackney has long been ethnically mixed. Today the borough is home to slightly over 200,000 residents, nearly $40 \%$ of whom are foreign-born. Africans, immigrants from the Caribbean, South Asians, Turks and Turkish-speaking members of other national/ethnic groups (Kurds, Turkish Cypriots), and Chinese live in Hackney in sizeable numbers. Spaniards, Greeks, Italians, Jews, and Poles are represented in smaller numbers. Hackney has one of the largest refugee and asylum-seeker populations in London. Next to its long history of having an ethnically mixed population, two other factors, on Wessendorf's account, have made diversity a 'commonplace' feature in 
Hackney: a high turnover of (mixed) population, and a significant proportion of settlers with previous histories of residing in mixed neighbourhoods who, therefore, possess the 'intercultural capital' helpful in navigating socioculturally diverse environments.

The 2008/2009 Hackney Place Survey quoted by Wessendorf [37, p. 4] showed that "almost four out of five residents $\ldots$ [thought] that people from different backgrounds get on well together". This actively sympathetic civility towards diversity has been accompanied by the practical "ethos of mixing". Conversely, resident groups that maintain their separateness (e.g., Orthodox Jews) are subject to shared negative comments from the locals. Wessendorf distinguishes three realms of intercultural relations in Hackney: public, semi-public or what she calls "parochial", and personal. Her ethnographic investigation focuses specifically on the semi-public/parochial spaces. Intergroup relations in parochial spaces are personal encounters that regularly occur between people in public places: on the streets, in the shops, beauty parlours, cafés, local clubs, public gardens, at special-occasion public events such as parties or residents' meetings with the local council etc.

Thus, the Algerian tailor at a local market area makes West African clothes because a considerable number of his customers come from that region. To facilitate their communication with the merchant and his attending family members, the customers have learned some words in Arabic with which they greet them, express their appreciation, and say good-bye. The Turkish owner of a corner shop sells Polish beer and Sauerkraut to please his Polish customers. He has also learned Polish greetings to welcome his customers who tell him about their daily experiences. The weekly coffee morning for parents at a local primary school and local knitting club gatherings, primarily attended by women - usually in attendance are white British women, British Pakistanis, British Guyanese, Italians, Nigerians from different ethnic groups, and Turkish women-provide occasions for cross-group socializing as the participants talk about teachers, children's educational problems, and their workplaces. "Regular contact at the school gates or when dropping off children at nursery" [37, p. 8] likewise sustains friendly relations across different ethnoreligious groups. The neighbourhood streets and shops run by representatives of different groups-Turks, Vietnamese, white Brits, Pakistanis, Jamaicans - and regularly frequented by the residents, men and women, offer another venue for interaction. As Wessendorf [38, p. 417] notes, Turkish, Vietnamese, and other foreign-language-speaking shopkeepers, restaurateurs, barbers, and owners and employees of beauty parlours communicate with customers from different groups through local interpreters who are usually at hand and eager to help. There is also an important sensuous dimension to these intercultural contacts, namely, the internalization by the participants of shapes, smells, and tastes different from the ones they were brought up with: Asian spices, halal hot dogs, Italian pasta, Turkish delight, Vietnamese grilled fish, Polish sausages, sandalwood and Egyptian musk. Altogether, they make for the daily experience of our-neighbourhood-as-England. Visible and invisible differences among the participants in intergroup encounters in Hackney regarding their religious commitments, political persuasions, and lifestyles as well as the existing prejudices underlying them, are "bracketed out" by those involved in such exchanges, Wessendorf reports, who, instead, focus on what she calls "commonalities", i.e., the shared aspects of their habitats and lifestyles.

My next example is Mission District, a solidly middleclass neighbourhood in San Francisco (information about it comes from Edwords [41], Miller [42], Rosenbaum [43], de Grauuw [44], and my personal experience of living there in the summer of 1998). The Mission's early twentiethcentury ethnic mosaic of residents of diverse European origins-Spanish, Irish, German, Italian, Scandinavian, Jewish, and Slavic - has been further enriched in the postwar era with the settlement of Asians - especially Chinese, Filipinos, Koreans, and Vietnamese - and large numbers of Mexicans, as well as Hawaiians, East Indians, and AfricanAmericans. In terms of their occupational pursuits the Mission's residents are also a diverse group. Especially on the western side of the neighbourhood they are mostly well educated (in the German sense of Bildung), comprising artists of all varieties experimenting with counter-culture, members of the free professions practicing alternative lifestyles, and some unconventionally-minded academics and graduate students from San Francisco University and Berkeley. They are hetero-, homo- and bisexual; young and elderly; religious and agnostic.

The Mission has a vibrant social and cultural life: numerous clubs, bars, food markets, popular theatres, art performances, and street entertainment are attended-and staffed-by a mix of ethnic-, sexual-, and age-group members who interact with each other at these occasions (rather than 'sticking with their own kind'). Open meetings and debates on local issues are regularly held in the neighbourhood - in situ or via the internet. Disagreements are worked out in a give-and-take manner. People from different groups also regularly visit each other's homes, exchange email and SMS messages, and form personal friendships. Through these channels, they not only express an empathetic interest in learning about the traditions and lifestyles of members of other groups, but also reciprocally 'borrow' bits and pieces thereof from each other.

The Mission residents share with their Hackney counterparts a 'naturalized' recognition of difference and an active partaking in this diversity, but they appear to do so with a more personal empathy, which, unlike the residents of Hackney, they also extend to the private sphere. During my sojourn in the Mission I did not detect, nor did 
I find reported in any local studies I read, any hierarchical ordering of people by colour, sexual orientation, or age, either in the public space or in personal interactions. As a matter of fact, the local political correctness code strictly forbids categorizing of the world into any 'essentializing' labels.

San Francisco has an enduring historical tradition, dating back to the late nineteenth century, of attracting 'freespirited', nonconformist settlers, and of a city politics, which has traditionally been informed by a tolerant, openminded civic culture, reflected since the $1960 \mathrm{~s}$ by successive 'rainbow coalitions' of political leaders with different skin colours, religious beliefs, and sexual orientations. This has compelled the municipal authorities actively to promote multiculturalism in the city's economic, civic-political, and socio-cultural life-another feature absent in Hackney. This includes efforts to encourage intergroup contacts also in residents' private lives by highlighting instances of emergent cross-cultural friendships and promoting various joint initiatives in the neighbourhoods, after school and after work.

These hands-on multiculturalist activities have been particularly intense in the Mission neighbourhood, probably because the concentration of people whose professions - arts, literature, humanities - and attendant life orientations foster explorative, open-minded attitudes towards the world and the people in it, is higher here than elsewhere in the city. A lack of significant residential or economic competition among the resident groups has upheld the friendly coexistence of their members, and a low level of residential racial, ethnic, and sexual (gay vs. heterosexual) segregation has facilitated everyday contacts. These features of the Mission have, in turn, attracted a particular kind of people: people who are cosmopolitan or, as observers call them, "bohemian" in mind and spirit, whose individual characteristics, reciprocally, sustain the multicultural profile of the neighbourhood in which they live. As they engage in the everyday activities of their neighbourhood, its residents compose and re-compose over time their interests and practices into changing constellations, creating a variety of local (sub) cultural features: faces, pronunciations, sights, smells, and sounds.

The final illustration of a setting conducive to immigrants' multicultural integration trajectories that I want to present for the purposes of this discussion is Ashfield, a lower-middle-class suburb west of Sydney, Australia. The information about Ashfield comes from the ethnographic investigation Amanda Wise [45-49] conducted there in the period 2002-2005 as well as my correspondence with Wise in July 2016 and Ashfield websites. Until World War II, Ashfield's population was almost entirely Anglo-Celtic, but during the post-war decades it became increasingly mixed, first with the influx of Italians, Greeks, and Poles (1950s/60s), then of Lebanese and Turks $(1970 \mathrm{~s} / 80 \mathrm{~s})$, and, most recently, of large numbers of Indian and Chinese settlers. Of the total population of slightly over 22,000 in 2011 , only 40 -odd percent were Australian-born; among the foreign-born, 15 percent were from China and 6 percent from India.

With a majority of residents being foreign-born and onefifth of the population speaking a foreign language (mainly Chinese) at home, Ashfield is an unmistakably multi-ethnic place. More tangibly than statistical figures, the neighbourhood's sights and smells palpably testify to its diversity: ubiquitous shops with signs in foreign languages display foreign-looking merchandise, fruit and vegetable markets offer Australian as well as exotic-tasting produce; eating places from a dozen corners of the world. When I checked the restaurants on one of the Ashfield websites, I found a staggering 504 of them just in the area around Liverpool Street and Norton Street. About $60 \%$ of them were Chinese, the rest Australian/English, Indian, Italian, Greek, Polish, Thai, Japanese, Mexican, and Spanish. Small food courts, in particular, offering a global variety of cuisines served on long tables shared by the customersAnglos, Italians, Indians, Chinese, Pacific Islanders, Sri Lankans, Sudanese, Filipinos, Iraqi, Portuguese, Poles, Greeks, Lebanese, Koreans [45, pp. 87-8]-provide occasions for friendly chats and access to neighbourhood news.

Wise describes a number of other quotidian crosscultural contacts among Ashfield's residents. These include the inter-ethnic neighbourly exchange of gifts such as backyard-grown vegetables - tomatoes, figs, chillies, curry leaves - between Lebanese, Italian, Indian, and Anglo neighbours usually accompanied by conversations about gardening skills [48]; and "bringing a plate" with homecooked food to local gatherings, which creates opportunities for discussions about recipes and, Wise[45, pp. 100-101] notes, "allows different food preferences to be directly incorporated into a shared gathering". As these contacts and exchanges between residents from different national/ethnic groups become 'naturalized' through their regularity, the participants begin to acquire and use some basic competence in each other's languages, 'codeswitching' (with the occasional faux pas) as they engage with representatives of different groups. As an Anglo Ashfield resident explained: "I will say a ni how (how are you) to them, in the Asian places. When it was gong xi fatt choy (Chinese New Year) in February, I had heard from Mary and Edward, the Chinese couple who run the chemist, about the little red bags they give in China ... so I got some little red bags ... and gave [them] to Mary and Edward, to the Chinese fellow who does my massage, and [just in case] to the Vietnamese lady in the bread shop" [49, p. 180-81].

As the multi-ethnic character of Ashfield has become a fact of everyday life, some residents - in particular, elderly white Anglo residents - have had problems adjusting to this change. They feel especially confused and alienated by the sensuous or, as Wise [47] calls it, haptic displays of this transformation involving their tactile, kinaesthetic, and proprioceptive senses: unfamiliar buildings and foreign- 
looking shops on the main street, different body languages of people, which they often (mis)conceive as impolite, intense exotic smells, which annoy their olfactory senses, voices, which they find too loud and screechy [49]. This resentment among the elderly of Ashfield is primarily directed towards the most recent-and most numerous and visible - arrivals, the Chinese. As some of them explain: "I regarded Ashfield as my suburb, my shopping centre. There are my shops, you had a friendly face. Today my shops have been replaced by other shops where I am not welcome. Mostly you go into the shops as a non-Chinese, and the attention is curt, off-hand, unhelpful” [47, p. 8]; “Ashfield's just unattractive now. Not one shop is attractive. They don't have pretty windows, it's all busy busy busy ... Some of the shops you wouldn't even know what they are" [49, p. 175].

On the other hand, during the four years of her fieldwork in Ashfield, Wise observed interesting changes in the orientations and practices of the otherwise frustrated elderly residents - she calls them "hopeful moments". As a historical sociologist who conceptualizes social life in terms of processes of becoming, I find her insight into a possible transformation-in-the-making - in the form of apparently multiplying instances of amicable mutual involvements between Anglo/European elderly residents and members of the new ethnic groups in Ashtonparticularly appealing. Bill, who is in his eighties and widowed, is being helped with everyday chores by Mai, his Chinese neighbour; Esther and John, a couple in their 70s, are deeply moved by their Chinese neighbour watering their plants; a new resident in the neighbourhood, a Filipina woman, gives a house-warming party and also invites several lonely elderly Anglo ladies to cheer them upwhich leads to a firm friendship between the hostess and her guests; culture-specific gifts offered by old-time residents to their new foreign neighbours, like the earliernoted red bags for the Chinese New Year gradually lead to mutual visits; and - perhaps the most picturesque of allat the annual Ashfield Seniors Spring Fair, attended by Anglo and other ethnic group representatives, everybody jumps up, links their arms and begins to dance to the tune of a Greek accordion musician playing "Zorba".

Extraordinary occurrences like this last one, Wise [49] notes, ensuing in a common (non-ethnic) space, can work as watersheds in "interculturalizing" social settings and relations. In their study of another multi-ethnic suburb of Sydney called Lakemba, Wise and Velayutham [50] note the importance of trend-setting individuals who "knit together connections between people of different backgrounds in the community". One such person is the owner of a South Asian Muslim shop, Mrs Nazar, who "greets everyone who comes into the shop with a "hello darling, how are you today?' (With the rolling 'Rs' of her Sumatran accent). She chats to all her customers, exclaims at our 'beautiful children' and eating there is punctuated by calls of 'Apa Kabar?' 'Terimah Kasih' (thank you), 'Bagus bagus' (good good) and 'jumpa lagi' (see you later), which everyone seems to understand, regardless of whether or not they speak Bahasa Indonesian". Wise does not mention similar "bridge constructors" in Ashfield. Should such people emerge, they would likely accelerate the process of cross-group ice-breaking between its elderly residents and new arrivals.

The three local settings reviewed here differ in their geophysical layouts and urban infrastructures, their historical traditions, the ethnic/racial/religious composition of their resident populations, and the foci of intergroup contacts. Consequently, they generate different forms of multicultural conviviality and one would, therefore, expect them to channel immigrant residents' multicultural incorporation along different paths in terms of the composition of its constitutive elements, the scope of coverage, and the intensity of attachments is concerned. The most encompassing modes of multicultural integration would be likely to evolve in the Mission District, followed by Hackney and Ashfield. Each of them in its own way represents a case of ambivalent conviviality. As a result, local processes of immigrants' multicultural integration would be somewhat bumpy, depending on the participants' origins, preferences, and aspirations. The investigation of such differing trajectories awaits the attention of interested researchers. In preparation of such undertakings, in the next section I offer a provisional overview of circumstances, which contribute to the emergence of multicultural trajectories of immigrants' integration into the host society.

\section{Multicultural Modes of Immigrants' Integration: Contributing Factors}

I have assembled features conducive to multicultural modes of assimilation on the micro-level, the level of the immediate environment and the participating groups and individuals, from various studies of locally embedded 'prosaic interactions' between members of different ethnic, racial, and religious groups in various localities conducted by urbanists, urban geographers and sociologists examining the sharing of space in global neighbourhoods $[51,8,52,53]$; by social psychologists studying "multicultural persons" [54]; by anthropologists and ethnographers who analyse the everyday functioning of "conviviality" in (sub)urban settings [55,56,39,37,57]; and by sociolinguists, especially those investigating "heteroglossia" or polylingualism — which, as opposed multilingualism, i.e., the knowledge of several separate languages, mixes and fuses components such as words, pronunciations, or styles of speech taken from different languages [58] —in ethnically plural neighbourhoods [5862].

The factors springing from the broader/national contexts that codetermine local lives I have gathered from studies, which discuss multiculturalism in terms of the institutional 
and legal arrangements and sets of policies that recognize and/or facilitate sociocultural diversity in today's societies. The literature on multiculturalism conceived in this vein is too vast to be referenced here; for good reviews of this approach, see [63-65].

The factors contributing to the emergence of multicultural paths of immigrants' integration into the host society are presented in Table 1. Before we proceed with the discussion, I should emphasize that this long (and most likely not exhaustive) list does not imply that all of the enumerated circumstances co-shape each and every instance of the emergent multicultural trajectories of newcomers' adaptation. Rather, time- and place-specific constellations of the factors relevant in particular cases should be identified by the researcher and, if the study involves more than one locality/group, compared across the examined instances.

I comment on the factors whose presence or absence in the table may not appear obvious to the readers, either because they were not noted in my presentation of empirical examples in the previous section, or because their inclusion in or exclusion from the table does not conform to the accustomed social-science models of assimilation.

Table 1. Factors Contributing to the Emergence of Multicultural Modes of Integration

Individual Characteristics/Situations

(i) intercultural capital, especially skills (also linguistic) of and advance acculturation into recognition/welcoming of cultural diversity and negotiatory (rather than confrontational) approach to differences/conflicts

(ii) accustomed perceptions, normative prescriptions, and personal concern with/interest in cultural differences/others, and flexibility of these orientations/worldviews (here: age factor as indicator of flexible vs. set ways of life/worldviews)

(iii) membership in/commitment to religious/ideological communities/beliefs founded on the idea of equality vs. superiority/separation/open war with members of other groups

(iv) residential/work/past-time everyday contact with vs. isolation from members of other groups

(v) intensity/frequency of experience of prejudice/discrimination in the larger, also local society

(vi)economic and/or residential competition with/sense of threat from members of other groups and/or distributive unfairness on the part of local authorities and -important—presence of opportunities in the local public realm to talk about/negotiate these issues

(vii) duration, sequence, and regularity of occurrence of (iii) through (vi) above

Local Society

External (Surrounding) Society

(i)ethnically/racially/religiously diverse resident population

(ii)availability of public spaces and occasions whose layout/infrastructure/organization generates 'connective sensibilities" among participating members of resident groups

(iii)structure of the economy and, especially, presence/absence of segmented labour markets/ethnic occupational niches

(iv)degree of inclusiveness of local public culture/discourse and active involvement of the local authorities/institutions on behalf of inter-group contacts/conviviality (including managing inter-group differences/resolving conflicts in negotiatory, compromise-seeking fashion)

(v) historical traditions/collective memory of inclusion/exclusion of different groups/ways of life and tolerance/intolerance of 'others'

Resident Groups

(i) level of residential/work segregation and presence/absence of opportunities for face-to-face social contacts in neighbourhoods and at work

(ii) presence and severity of inter-group conflicts/competition for jobs, residence, and political recognition and shared perceptions of threat by others and/or distributive unfairness on the part of local authorities, combined with—important—availability and recognition by involved group of the opportunities in the local public realm to talk about/negotiate these inter-groupconflicts

(iii) degree of ethnic/racial/religious groups' institutional completeness

(iv) degree of resident groups' socio-cultural enclosure/openness sanctioned by religious/ideological norms

(v) degree of embeddedness and 'mendability' (capacity to bracket out or change/adjust) of resident group members' shared perceptions/stereotypes of other groups and their religiously/ideologically sanctioned sense of superiority/inferiority vis-à-vis others

(vi) presence and degree of involvement of charismatic "bridge constructors" among members of different resident groups

(vii) presence and strength of a sense of shared territory (neighbourhood, town) by members of different resident groups

(viii)occurrence of extraordinary, ice-breaking events bringing together members of different resident groups

(ix) regularity of occurrence of (ii),(vi), and (vii) above

Broader (National) Context

(i) legal system and policies regarding immigrants and multiculturalism which affect their local-level implementation

(ii) national media's representations of immigrants, ethnoreligious diversity, and the (dis)advantages of multiculturalism which regularly reach local residents 
I will begin with the individual characteristics likely to contribute to the emergence of multicultural trajectories of immigrants' incorporation into the host society. As demonstrated by the socioeconomically diverse settings reviewed in the previous section, residents' class position - or, for that matter, the class composition of the neighbourhood-does not affect the emergence of multicultural conviviality among residents unless they feel insecure or threatened. A research team of which I was a member in in 2012/13 (we never moved beyond the pilot study) found that, among recent East European (im) migrants in Berlin and London, the class factor-in this case, specifically, the respondents' educational level-had no impact on their acquisition of multicultural ideas and practices. In fact, a number of poorly educated (im) migrants we interviewed declared a much stronger commitment to the values of multiculturalism than did their highly educated professional counterparts.

Among the insecurities and threats that do have the potential to weaken multicultural conviviality are a rapid ethnic/racial/ religious re-composition of the neighbourhood, especially if it is triggered by a significant numerical increase of settlers of a particular origin whom the established residents perceive as undesirable; competition for residential and/or business areas and jobs; and/or a sense of what I call in the table "distributive unfairness" in the assignment of housing, jobs, offices, and other allocations by local authorities/institutions. However, in and of themselves, these factors do not necessarily preclude the emergence of multicultural conviviality. They can be effectively counter-balanced by efforts on the part of local leaders/institutions to ameliorate the problems through public education, media, and intergroup negotiations that individual residents follow/participate in, and/or by the latter's ability, Hackney-style, to factor these issues out when encountering 'others'. One could also argue in this context that the 'optional' character of multicultural conviviality and multicultural modes of integration, i.e., the situational, shifting constellations of their constitutive components, allow the actors to pickchoose-and-rearrange the groups, customs, and traditions they draw from in composing their own identities, lifestyles, and commitments.

In the table, I have included "accustomed perceptions/lifestyle" as a factor that can potentially influence people's readiness to engage in amiable relations with 'others'. For example, as we have seen in the case of Ashfield, the advanced age of residents - treated as an indicator of firmly set life orientations - can play a role in hindering the emergence of multicultural conviviality.

Finally, as I have also indicated in Table 1, and this is important, factors related to the temporal dimensions of our everyday lives also contribute to the emergence of multicultural modes of immigrants' integration. This concerns the duration and regularity of experiences/events relevant to multicultural conviviality. I have included these factors not because I assume that these circumstances of our everyday lives are always at play in shaping our crosscultural activities, but because, in my opinion as a sociologist-historian, they have not been given sufficient attention in social-science studies of immigrants' pursuits (in this context see, for example, the excellent studies by two American historical sociologists, Ronald Aminzade [66] and Andrew Abbott [67], on the causal effects of time on the direction and outcomes of our activities). For example, the impact of a prolonged regular occurrence of unpleasant encounters with 'others'-be it prejudiced/discriminating members of the mainstream society or untrustworthy or disorderly foreign residents in the neighbourhood - is likely to overwhelm that of a series of occasional friendly exchanges.

In terms of the characteristics of the local environment/resident groups that are conducive to the emergence of multicultural modes of newcomers' integration into the local society, the presence of manageable public spaces that invite face-to-face intergroup contacts is worth emphasizing, not least because it is often overlooked in social-science studies of immigrants' adaptation. They need to be not too big, not too rushed, with places to sit or do things together and socialize. As Amanda Wise found out in Ashfield, and I also noted in San Francisco, large shopping malls do not seem to serve this purpose. Although attended by multiethnic crowds, they are anonymous, quick-paced, do-yourown-business-and-go settings that make people invisible to each other and, thus, do not generate connective sensibilities that facilitate a sense of the ordinariness of diversity and a normalization of inter-cultural involvements.

The other noteworthy factors conducive to the emergence of multicultural conviviality listed in the table include, on the one hand, a minimal-to-small number of institutionally complete resident groups in the neighbourhood/town whose life orientations and practices are characterized by a high degree of religiously or ideologically sanctioned sociocultural enclosure or inwardness. Keeping themselves strictly separate, Orthodox Jews in Hackney to some extent spoil an otherwise successful multicultural exchange in the neighbourhood; a greater or prevailing number of such groups could prevent the atmosphere and everyday practice of conviviality altogether. On the other hand, as the empirical examples from the previous section demonstrate, the presence of intergroup conflicts and negative stereotypes does not, in and of itself, seem to preclude the emergence of multicultural conviviality. Here too, at the group level, the locally available and practiced forms of difference management and conflict/threat resolution seem to weigh more heavily than the presence/absence of conflicts as such.

Turning to the broader/national contexts, which contribute to the emergence of multicultural modes of 
immigrants' integration, one noteworthy factor, which is not included in the table, is the state of the host-country economy. I have not included it because, to my mind, it is not the current state of the national economy as such that may favour or inhibit multicultural integration trajectories at the local level but its effect on those local contexts. What particular features/mechanisms of the respective local economies may temporarily shield them, or allow them to benefit, from the effects of national/regional/global economic trends still needs investigation

\section{Conclusions}

The main purpose of this discussion has been to interest immigration scholars in the possibility of yet anothermulticultural - trajectory of immigrants' incorporation into the host society. Having identified their defining components, I have argued for a context-dependent, flexible understanding of multicultural modes of integration, which allows for the expansion and contraction of their contents and intensity with changing circumstances. Moreover, I have argued that the processes of multicultural adaptation evolve primarily in local settings through the participating actors' immediate experiences. I then offered some empirical examples of the sorts of local settings whose characteristics facilitate everyday multicultural conviviality among members of different resident groups, and presented a provisional list of conditions conducive to the emergence of multicultural modes of immigrants' incorporation into local society. Should my suggestions trigger an interest among students of immigration and ethnicity, the next steps would involve empirical investigations of the forms, contents, and multi-level contexts facilitating/hindering processes of multicultural integration, followed by a refinement of the definitional components of such developments and a theoretical reflection on how, specifically, they evolve or recede.

\section{REFERENCES}

[1] Steven Vertovec, "Migration, Cities, Diversities 'Old' and 'New'", in Steven Vertovec ed., Diversities Old and New. Migration and Socio-Spatial Patterns in New York, Singapore, and Johannesburg. Basingstoke: Palgrave Macmillan, 2015, 1-22.

[2] Magdalena Nowicka and Steven Vertovec. "Comparing Convivialities: Dreams and Realities of Living-withDifference", European Journal of Cultural Studies, Vol. 17 No. 4 (2014). 341-356.

[3] Paolo Boccagni. "(Super) diversity and the migration-social work nexus: a new lens on the field of access and inclusion?' Ethnic and Racial Studies, Vol. 38 No. 4 (2014). 608-620.

[4] Beatriz Padilla, Joana Azevedo and Antonia Olmos-Alcaraz. "Superdiversity and conviviality: exploring frameworks for doing ethnography in Southern European intercultural cities", Ethnic and Racial Studies, Vol. 38 No. 4 (2015). 621-635.

[5] Fran Meissner and Steven Vertovec. "Comparing superdiversity”, Ethnic and Racial Studies, Vol. 38 No. 4 (2015). 541-555.

[6] John Logan, and Charles Zhang. "Global Neighbourhoods: New Pathways to Diversity and Separation", American Journal of Sociology, Vol.115 No. 4 (2010). 1069-1109.

[7] Ash Amin. "Collective culture and urban public space", City, Vol. 12 No. 1 (2008. 5-24.

[8] Alex Rhys-Taylor. "The essences of multiculture: a sensory exploration of an inner-city street market", Identities: Global Studies in Culture and Power, Vol. 20 No. 4 (2013). 393-406.

[9] Peter Kivisto. "Integration and Assimilation: The Core Concepts and Three Contemporary Developments," Elliott Barkan ed., Immigrants in America. Santa Barbara, CA: ABC-Clio, 2012, 1621-1636.

[10] Ethnic and Racial Studies special issue: Assimilation and Integration Theories, Vol. 37 No. 7 (2010).

[11] Maurice Crul. "Super-diversity vs. assimilation: how complex diversity in majority-minority cities challenges the assumptions of assimilation", Journal of Ethnic and Migration Studies, Vol. 42 No. 1 (2016). 54-68.

[12] Lyn Lofland. "Social life in the public realm. A review", Journal of Contemporary Ethnography, Vol. 17 No. 4 (1989). 453-482.

[13] Peter Kivisto. Multiculturalism in a Global Society. Oxford: Blackwell, 2002.

[14] Jeffrey Alexander. "Theorizing the 'Modes of Incorporation': Assimilation, Hyphenization, and Multiculturalism as Varieties of Civic Participation", in Peter Kivisto ed., Incorporating Diversity. Rethinking Assimilation in a Multicultural Age. Boulder, CO: Paradigm Publishers, 320-336.

[15] Will Kymlicka. Multicultural Citizenship: A Liberal Theory of Minority Rights. Oxford: Clarendon Press, 1995.

[16] Charles Taylor. Multiculturalism and 'The Politics of Recognition'. Princeton: Princeton University Press, 1992.

[17] Frans De Waal. The Age of Empathy. Louisville, KY: Harmony House, 2009.

[18] Michael Walzer. "Two kinds of universalism", in The Tanner Lectures on Human Values Vol. 11. Salt Lake City: University of Utah Press, 1990, 509-556; https://tannerlectures.utah.edu/_documents/a-toz/w/walzer90.pdf.

[19] John Clayton. "Thinking spatially: towards an everyday understanding of inter-ethnic relations", Social \& Cultural Geography, Vol. 10 No. 4 (2009) 481-498.

[20] Metter Louise Berg and Nando Sigona. "Ethnography, diversity and urban space", Identities: Global Studies in Culture and Power, Vol. 20 No. 4 (2013). 347-460.

[21] Ethnic and Racial Studies special issue: Super-Diversity, 
Vol. 38 No. 4 (2015).

[22] Horace Kallen. "Democracy versus the Melting-Pot: A Study of American Nationality, Parts I and II", The Nation, 18 February 1915, 190-194 and 25 February 1915, 217-220.

[23] Randolph Bourne. "Trans-national America", Atlantic Monthly, Vol. 118 No. 1 (1916). 86-97.

[24] Louis Adamic. From Many Lands. New York: Harper \& Brothers, 1940.

[25] Herbert Gans. "Toward a Reconciliation of 'Assimilation' and 'Pluralism': The Interplay of Acculturation and Ethnic Retention", International Migration Review, Vol. 31 No. 4 (1997). 875-893.

[26] Mary Waters. Ethnic Options: Choosing Identities in America. Berkeley: University of California Press, 1990.

[27] Mary Waters. "Ethnic identities in the future: the possible effects of mass immigration and genetic testing", Ethnic and Racial Studies, Vol. 37 No. 5 (2014). 766-769.

[28] Nathan Glazer. "We Are All Multiculturalists Now", in Peter Kivisto and Georganne Rundblad ed., Multiculturalism in the United States. Thousand Oaks, CA. Pine Forge Press, 2000, 445-454.

[29] Herbert Gans. "The coming darkness of late-generation European American ethnicity", Ethnic and Racial Studies, Vol. 37 No. 5 (2014). 757-765.

[30] Jeremy Waldron. "What is Cosmopolitan?" Journal of Political Philosophy, Vol. 8 No. 2 (2000). 227-243.

[31] Thomas Faist. "Diversity - a new mode of incorporation?" Ethnic and Racial Studies, Vol. 32 No. 1 (2009). 171-190.

[32] Susanne Wessendorf. "Researching social relations in super-diverse neighbourhoods", IRiS Working Paper Series No. 2, University of Birmingham, 2014; https://www.birmingham.ac.uk/Documents/college-socialsciences/social-policy/iris/2014/working-paperseries/IRiS-WP-2-2014.pdf.

[33] Nasar Meer and Tariq Modood. "How does Interculturalism Contrast with Multiculturalism", Journal of Intercultural Studies, Vol. 33 No. 2 (2012): 175-196.

[34] Charles Taylor. "Interculturalism or Multiculturalism?" Philosophy and Social Criticism, Vol. 38 Nos. 4-5) (2012). 413-423.

[35] Gerard Bouchard. "What is Interculturalism?" McGill Law Journal, Vol. 56 No. 2 (2011). 436-468.

[36] Ash Amin. "Ethnicity and the multicultural city: living with diversity", Environment and Planning, Vol. 34 No. 6 (2002). 959-980.

[37] Susanne Wessendorf. "'Being open, but sometimes closed'. Conviviality in a super-diverse London neighbourhood", European Journal of Cultural Studies, Vol. 17 No. 4 (2013). 1-14.

[38] Susanne Wessendorf. "Common place diversity and the 'ethos of mixing': perceptions of difference in a London neighbourhood", Identities: Global Studies in Culture and Power, Vol. 20 No. 4 (2013). 407-422.

[39] Susanne Wessendorf. "Commonplace diversity: Social interactions in a super-diverse context", Working Paper \#10-11 of the Max Planck Institute for the Study of Religious and Ethnic Diversity, 2010; http://www.mmg.mpg.de/en/publications/workingpapers/2010/wp-10-11/.

[40] Sarah Neal, Katy Bennett, Allan Cochrane, and Giles Mohan. "Living multiculture: understanding the new spatial and social relations of ethnicity and multiculture in England", Environment and Planning, Vol. 31 No. 2 (2013). 308-323.

[41] Clarence Edwords. Bohemian San Francisco. San Francisco: General Books Publications, 2009.

[42] Mike Miller. A Community Organizer's Tale: People and Power in San Francisco. Berkeley, CA: Heyday Books, 2009.

[43] Fred Rosenbaum. Cosmopolitans: A Social and Cultural History of the Jews in the San Francisco Bay. Berkeley: University of California Press, 2009.

[44] Els de Grauuw. Making Immigrant Rights Real: Nonprofit and the Politics of Integration in San Francisco. Ithala: Cornell University Press, 2016.

[45] Amanda Wise. "Moving Food: Gustatory Commensality and Disjuncture in Everyday Multiculturalism", New Formations: Journal of Culture/Theory/Politics, Vol. 74 No. 1 (2011). 82-107.

[46] Amanda Wise. "'You wouldn't know what's in there would you?' Homeliness and 'foreign' sings in a translocal suburb", in Katherine Brickell and Ayona Datta eds., Translocal Geographies: Spaces, Places, Connections. Aldershot: Ashgate, 2011, 93-108.

[47] Amanda Wise. "Sensuous Multiculturalism: Emotional Landscapes of Inter-Ethnic Living in Australian Suburbs", Journal of Ethnic and Migration Studies, Vol. 21 No. 1 (2010). 1-21.

[48] Amanda Wise. "Everyday Multiculturalism: Transversal Crossings and Working Class Cosmopolitans", in Amanda Wise and Selvaraj Velayutham eds., Everyday Multiculturalism. Basingstoke: Palgrave Macmillan, 2009, 21-45.

[49] Amanda Wise. "Hope and Belonging in a Multicultural Suburb", Journal of Intercultural Studies, Vol. 26 Nos. 1-2 (2005). 171-186.

[50] Amanda Wise and Selvaraj Velayutham. "Conviviality in everyday multiculturalism: Some brief comparisons between Singapore and Sydney", European Journal of Cultural Studies, Vol. 17 No. 4 (2014). 406-430.

[51] Amanda Wise and Selvaraj Velayutham eds., Everyday Multiculturalism. Basingstoke: Palgrave Macmillan, 2009.

[52] Jeffrey Hou. Transcultural Cities: Border-Crossing and Placemaking. London: Routledge, 2013.

[53] Sophie Watson and Anamik Saha. "Suburban drifts: Mundane multiculturalism in outer London", Ethnic and Racial Studies, Vol. 36 No. 12 (2013). 2016-2034.

[54] Bernice Lott. Multiculturalism and Diversity. A Social Psychological Perspective. Oxford: Blackwell, 2010. 
[55] Steven Vertovec ed. Anthropology of Migration and Multiculturalism. London: Routledge, 2011.

[56] Steven Vertovec ed. Diversities Old and New. Migration and Socio-Spatial Patterns in New York, Singapore, and Johannesburg. Basingstoke: Palgrave Macmillan, 2015.

[57] Christian Karner and David Parker. "Multiculture and Community in New City Spaces", Journal of Intercultural Studies, Vol. 32 No. 2 (2011). 133-150.

[58] Ben Rampton. "From 'Multi-ethnic adolescent heteroglossia' to 'Contemporary urban vernaculars", Language and Communication, Vol. 31 No. 4 (2011). 276294.

[59] Ben Rampton. Crossing: Language and Ethnicity among Adolescents. Manchester: St. Jerome Publishing, 2005.

[60] Normann Jorgensen. "Polylingual Languaging Around and Among Children and Adolescents", International Journal of Multilingualism, Vol. 5 No. 3 (2008). 161-176.
[61] Sirpa Leppanen et al. "Young People's Translocal New Media Uses: A Multiperspective Analysis of Language Choice and Heteroglossia", Journal of Computer-Mediated Communication, Vol. 14 No. 4 (2008). 1080-1107.

[62] Adrienne Lo. "Codeswitching, speech community membership, and the construction of ethnic diversity", Journal of Sociolinguistics, Vol. 3 No. 4 (1999). 461-479.

[63] George Crowder. Theories of Multiculturalism: An Introduction. Cambridge: Polity Press, 2013.

[64] Tariq Modood. Multiculturalism: A Civic Idea. Cambridge: Polity Press, 2013.

[65] Michael Murphy ed. Multiculturalism: A Critical Introduction. Abington: Routledge, 2012.

[66] Ronald Aminzade. "Historical Sociology and Time", Sociological Methods and Research, 20(4): (1992). 456-480.

[67] Andrew Abbott. Time Matters: Theory and Method. Chicago: University of Chicago Press, 2001. 